\title{
Physician-assisted deaths under the euthanasia law in Belgium: a population-based survey
}

\author{
Kenneth Chambaere PhD, Johan Bilsen RN PhD, Joachim Cohen PhD, \\ Bregje D. Onwuteaka-Philipsen PhD, Freddy Mortier PhD, Luc Deliens PhD
}

Previously published at www.cmaj.ca

\section{ABSTRACT}

Background: Legalization of euthanasia and physicianassisted suicide has been heavily debated in many countries. To help inform this debate, we describe the practices of euthanasia and assisted suicide, and the use of lifeending drugs without an explicit request from the patient, in Flanders, Belgium, where euthanasia is legal.

Methods: We mailed a questionnaire regarding the use of life-ending drugs with or without explicit patient request to physicians who certified a representative sample ( $n=$ 6927) of death certificates of patients who died in Flanders between June and November 2007.

Results: The response rate was $58.4 \%$. Overall, 208 deaths involving the use of life-ending drugs were reported: 142 (weighted prevalence $2.0 \%$ ) were with an explicit patient request (euthanasia or assisted suicide) and 66 (weighted prevalence $1.8 \%$ ) were without an explicit request. Euthanasia and assisted suicide mostly involved patients less than 80 years of age, those with cancer and those dying at home. Use of life-ending drugs without an explicit request mostly involved patients 80 years of older, those with a disease other than cancer and those in hospital. Of the deaths without an explicit request, the decision was not discussed with the patient in $77.9 \%$ of cases. Compared with assisted deaths with the patient's explicit request, those without an explicit request were more likely to have a shorter length of treatment of the terminal illness, to have cure as a goal of treatment in the last week, to have a shorter estimated time by which life was shortened and to involve the administration of opioids.

Interpretation: Physician-assisted deaths with an explicit patient request (euthanasia and assisted suicide) and without an explicit request occurred in different patient groups and under different circumstances. Cases without an explicit request often involved patients whose diseases had unpredictable end-of-life trajectories. Although opioids were used in most of these cases, misconceptions seem to persist about their actual life-shortening effects.

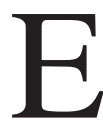

uthanasia and physician-assisted suicide are heavily debated issues in medical practice. In recent years, three European countries (Belgium and the Nether- lands in 2002, and Luxemburg in 2009) and two US states (Oregon in 1997 and Washington State in 2009) decriminalized euthanasia and physician-assisted suicide under formal conditions..$^{1-5}$ Canada is among a number of countries where the debate over legalization has flared up, with a proposed bill reaching Parliament and a pro-euthanasia proposal by the Quebec College of Physicians. ${ }^{6}$

Understandably, the issue of euthanasia triggers much emotion and can be fraught with speculative arguments. Opponents of euthanasia often argue that legalizing the procedure will lead to a rise in the use of life-ending drugs without a patient's explicit request, especially in vulnerable patient groups. ${ }^{7-10}$ Thus far, however, no indications of this have been found in studies of physician-assisted deaths before and after legalization in Belgium and the Netherlands. ${ }^{911,12}$ In Belgium, the percentage of deaths in which life-ending drugs were used remained stable, and the proportion without an explicit request from the patient decreased. ${ }^{12}$ Other studies have shown that euthanasia, physician-assisted suicide and the use of life-ending drugs without explicit patient request are not confined to countries where physician-assisted death is legal. ${ }^{13-16}$

In addition to knowing the overall occurrence of physician-assisted death, it is equally important for an adequately informed, empirically based debate to know its performance in vulnerable patient groups and the care put into the decision and performance. In light of legalization and its alleged effects on the use of life-ending drugs without patient request, it is also important to map similarities and differences between euthanasia and the use of life-ending drugs without explicit patient request. In this article, we report our investigation of demographic and clinical characteristics associated with physician-assisted deaths in Flanders, Belgium; the involvement of the patient, relatives and other caregivers in

From the End-of-Life Care Research Group (Chambaere, Bilsen, Cohen, Deliens) and the Department of Public Health (Bilsen), Vrije Universiteit Brussel, Brussels, Belgium; the Department of Public and Occupational Health, EMGO Institute for Health and Care Research, Expertise Center for Palliative Care (Onwuteaka-Philipsen, Deliens), VU University Medical Centre, Amsterdam, the Netherlands; and the Bioethics Institute Ghent (Mortier), Ghent University, Ghent, Belgium

CMAJ 2010. DOI:10.1503/cmaj.091876 
the decision-making process; reasons for the decisions; aspects of the treatment trajectory; and details of the performance in terms of drug use and the people administering the life-ending drugs.

\section{Methods}

\section{Study design}

In 2007 we conducted a large-scale study of death certificates in Flanders, the Dutch-speaking part of Belgium that has about six million inhabitants and 55000 deaths per year. We obtained a stratified sample of all death certificates from June to November 2007 of Belgian residents aged one year or older from the Flemish Agency for Care and Health. We assigned the certificates to one of four strata according to cause of death and the corresponding estimated likelihood of an end-of-life decision. Sampling fractions for strata increased proportionally with this likelihood. The resulting sample comprised 6927 death certificates, which represented $25 \%$ of deaths during the study period and about $12 \%$ of all deaths in Flanders in 2007. Details of the methodology for this review have been described elsewhere. ${ }^{17}$

A five-page questionnaire and covering letter explaining the study were sent to the attending physician in each case. A response was regarded as implicit consent to participate. If the physician did not respond after three reminders, a one-page questionnaire was sent enquiring about the reasons for nonresponse. Total anonymity for participating physicians and deceased patients was guaranteed through a rigorous mailing procedure involving a lawyer as intermediary between physicians and researchers. Information from the death certificates (patient sex, age, place of death and cause of death) was made available only after it had been coded, to preclude any identification of patient or physician. For the anonymity procedure, we received approval from the ethical review boards of the organizing universities, and recommendations from the Belgian Medical Disciplinary Board and the Belgian Federal Privacy Commission.

\section{Questionnaire}

We modelled the questionnaire after ones used and extensively validated in previous studies in Belgium and other European countries. ${ }^{11-13}$ For the present study, the questionnaire was validated through testing by a panel of physicians.

Physicians were asked about end-of-life decisions, defined as "medical decisions at the end of patients' lives with a possible or certain life-shortening effect." We identified cases as physician-assisted deaths if the physician gave an affirmative answer to the following question: "Was the death the consequence of the use of drugs prescribed, supplied or administered by you or another physician with the explicit intention of hastening the end of life or of enabling the patient to end his or her own life?" Additional questions dealt with the lifeending drugs used and who administered the drugs. Other sections of the questionnaire asked about the involvement of the patient, family and other caregivers in the decisionmaking process, the reasons for the decision, how long the patient had received treatment for the illness leading to death, the main goal of treatment in the last week before death and the estimated time by which the patient's life was shortened.

For the deaths with an explicit request from the patient, we classified them as euthanasia if someone other than the patient had administered the drugs and as physician-assisted suicide when the patient had administered the drugs.

\section{Statistical analysis}

We weighted the reported percentages to correct for the disproportionate stratification of deaths and to correct for differences between the response sample and all deaths in Flanders in 2007 relating to sex, age, province of death, place of death and cause of death (differences were found relating only to place of death). We conducted statistical analyses with SPSS 17.0 software, using the complex samples procedure to account for the stratified sample design and associated standard errors. We used the Fisher exact test to compare differences in distributions between physician-assisted death with explicit patient request (euthanasia or assisted suicide) and the use of life-ending drugs without explicit patient request; statistical significance was set at a $p$ value of less than 0.05 .

\section{Results}

We received questionnaires for 3623 of the 6927 deaths. For 725 of the remaining 3304 deaths, a response was not possible because the physician no longer had access to the patient's medical file because of a change of workplace, or the physician could not retrieve the identity of the patient. We removed these cases from the sample. The final response rate, therefore, was $58.4 \%$ (3623 of 6202 valid cases).

We identified 208 physician-assisted deaths: 142 (weighted prevalence $2.0 \%$ ) with an explicit request from the patient (137 euthanasia, 5 assisted suicide) and 66 (weighted prevalence 1.8\%) without an explicit request (Table 1). Euthanasia and assisted suicide predominantly involved patients less than 80 years old $(79.6 \%)$, those with cancer $(80.2 \%)$ and those dying at home $(50.3 \%)$. Of the cases without an explicit request from the patient, most involved patients who were 80 years of age or older $(52.7 \%)$, those without cancer $(67.5 \%)$ and those who died in hospital (67.1\%). The distribution of patient characteristics for life-ending acts without explicit request was similar to that for all other deaths in Flanders, except that it was performed more often in hospital and by clinical specialists.

The decision to end life was discussed with the patient in $22.1 \%$ of the cases without an explicit patient request (Table 2). In cases where the decision had not been discussed with the patient, the physician specified as reason(s) that the patient was comatose ( $70.1 \%$ of cases) or had dementia (21.1\%); in $40.4 \%$ of cases, the physician indicated that the patient had previously expressed a wish for ending life (not equivalent to an explicit request for euthanasia). Physicians specified that the decision had not been discussed with the patient because the decision was in the patient's best interest $(17.0 \%)$ or because discussion would have been harmful (8.2\%). Compared with euthanasia or assisted suicide, the use of life-ending drugs without an explicit patient request was 
discussed less often with other caregivers, but as often with the patient's family. Pain and the patient's wish for ending life were more often reasons for carrying out euthanasia or assisted suicide, whereas family burden and the consideration that life was not to be needlessly prolonged were more often reasons for using life-ending drugs without explicit patient request.

Assisted deaths with and without an explicit request from the patient differed significantly with regard to length of treatment of the terminal illness, the primary goal of treatment during the last week and the estimated time by which life was shortened (Table 3). In most cases in which euthanasia or physician-assisted suicide was performed, the patients had been treated for their terminal illness for more than 6 months $(80.3 \%)$, the goal of treatment in the last week was patient comfort $(94.3 \%)$, and life was shortened by 1 week or more $(44.5 \%)$. In contrast, the cases without an explicit request were more likely to have a shorter length of treatment of the terminal illness ( $<1$ month in $46.1 \%$ of cases), to have cure as a goal of treatment in the last week $(14.6 \%$ v. $1.2 \%$ of cases with an explicit request) and to have a shorter estimated time by which life was shortened $(<24$ hours in $47.9 \%$ of cases) (Table 3).

Compared with drugs used in euthanasia and assisted suicide, opioids were used far more often in the ending of life without an explicit patient request, especially when used as the sole drug (Table 4). In these cases, the dosage was strongly increased in the last 24 hours in $45.8 \%$, and the physician indicated it to be higher than needed to alleviate the patient's symptoms in $46.8 \%$ (data not shown). Nurses were more often involved in the administration of the drugs when there was no explicit request from the patient than in cases of euthanasia or assisted suicide.

\section{Interpretation}

We found that, five years after the euthanasia law was enacted in Belgium, euthanasia and assisted suicide occurred in $2.0 \%$ of all deaths in Flanders during the study period. They predominantly involved patients less than 80 years old, patients

Table 1: Characteristics of physician-assisted deaths and all other deaths in Flanders, Belgium, from June to November 2007

\begin{tabular}{|c|c|c|c|c|}
\hline \multirow[b]{2}{*}{ Characteristic } & \multicolumn{2}{|c|}{ Physician-assisted deaths; weighted \%* } & \multirow[b]{2}{*}{$p$ value $\ddagger$} & \multirow[b]{2}{*}{$\begin{array}{c}\text { All other } \\
\text { deaths, \%* } \\
n=3415\end{array}$} \\
\hline & $\begin{array}{c}\text { With patient's } \\
\text { explicit request† } \\
n=142\end{array}$ & $\begin{array}{l}\text { Without patient's } \\
\text { explicit request } \\
n=66\end{array}$ & & \\
\hline$\%$ of all deaths (weighted*) & 2.0 & 1.8 & & - \\
\hline Sex, male & 61.3 & 46.2 & 0.09 & 49.6 \\
\hline Age, yr & & & $<0.001$ & \\
\hline $1-64$ & 37.0 & 8.2 & & 17.0 \\
\hline $65-79$ & 42.6 & 39.1 & & 32.4 \\
\hline$\geq 80$ & 20.4 & 52.7 & & 50.6 \\
\hline Cause of death & & & $<0.001$ & \\
\hline Cardiovascular disease & 3.8 & 37.5 & & 34.3 \\
\hline Malignant disease & 80.2 & 32.4 & & 26.6 \\
\hline Respiratory disease & 4.7 & 10.8 & & 12.2 \\
\hline Disease of the nervous system & 7.2 & 3.6 & & 3.5 \\
\hline Other disease & 4.0 & 15.6 & & 23.4 \\
\hline Place of death & & & $<0.001$ & \\
\hline At home & 50.3 & 18.7 & & 23.1 \\
\hline Hospital & 41.9 & 67.1 & & 49.6 \\
\hline Care home & 3.4 & 12.5 & & 23.1 \\
\hline Other & 4.3 & 1.6 & & 4.1 \\
\hline Type of physician & & & 0.001 & \\
\hline General practitioner & 60.1 & 32.3 & & 43.4 \\
\hline Clinical specialist & 39.7 & 66.5 & & 50.2 \\
\hline Other & 0.2 & 1.2 & & 6.4 \\
\hline
\end{tabular}

*Percentages are weighted to correct for the disproportionate stratification of deaths and for differences in the distribution of patient characteristics (sex, age, province in which death occurred, place of death and cause of death) between study sample and all deaths. Percentages may not total 100 because of rounding. The discrepancy between the number of deaths and the weighted percentage is due to the oversampling of euthanasia cases in the sampling method.

tEuthanasia and assisted suicide.

¥Calculated using Fisher exact test, for comparison between physician-assisted death with and without explicit request from the patient. 
with cancer and patients dying at home; the drugs used most often were barbiturates and muscle relaxants, alone or in combination; and the severity of pain or other symptoms, the lack of prospects of improvement and the patient's wishes were the most common reasons for performing these acts.

The use of life-ending drugs without an explicit request from the patient occurred in $1.8 \%$ of the deaths in Flanders during the study period. Most of these cases involved patients
80 years or older and occurred in hospital. In the majority of cases, the patient was not involved in the decision, primarily because of coma or dementia; however, relatives and other caregivers were often consulted. Considerations involving the relatives and needless prolongation of life were reasons indicated by physicians for reaching the decision. Compared with euthanasia and assisted suicide, cases of assisted death without an explicit request from the patient had a shorter length of

Table 2: Decision-making process at the end of life in physician-assisted deaths

\begin{tabular}{|c|c|c|c|}
\hline \multirow[b]{2}{*}{ Process } & \multicolumn{2}{|c|}{ Physician-assisted deaths; weighted \%* } & \multirow[b]{2}{*}{$p$ value§ } \\
\hline & $\begin{array}{l}\text { With patient's } \\
\text { explicit request } \dagger \\
n=142\end{array}$ & $\begin{array}{l}\text { Without patient's } \\
\text { explicit request } \\
\quad n=66 \ddagger\end{array}$ & \\
\hline Decision discussed with patient & 100.0 & 22.1 & $<0.001$ \\
\hline Decision not discussed with patient & - & 77.9 & \\
\hline \multicolumn{4}{|l|}{ Reason for not discussing decision with patient** } \\
\hline Patient was comatose & & 70.1 & \\
\hline Patient had dementia & & 21.1 & \\
\hline Decision was clearly in patient's best interest & & 17.0 & \\
\hline Discussion would have been harmful to patient & & 8.2 & \\
\hline Other & & 10.1 & \\
\hline $\begin{array}{l}\text { Decision not discussed, but patient had previously } \\
\text { expressed a wish for ending life }\end{array}$ & & 40.4 & \\
\hline $\begin{array}{l}\text { Decision not discussed, but patient had a written } \\
\text { advance directivett }\end{array}$ & & 4.0 & \\
\hline Decision discussed with family & 77.4 & 79.4 & 0.84 \\
\hline Decision discussed with other caregivers & 89.1 & 71.0 & 0.010 \\
\hline Physician(s) & 77.8 & 58.4 & 0.026 \\
\hline Nurse(s) & 54.1 & 40.2 & 0.13 \\
\hline Caregiver(s) specialized in palliative care & 50.0 & 14.8 & $<0.001$ \\
\hline Decision discussed with no one & 0.0 & 6.5 & 0.05 \\
\hline \multicolumn{4}{|l|}{ Reason for decision** } \\
\hline Patient had severe pain & 59.9 & 33.2 & 0.001 \\
\hline Patient had severe symptoms other than pain & 72.6 & 57.5 & 0.05 \\
\hline Wish of the patient & 93.1 & 6.3 & $<0.001$ \\
\hline Wish of the family & 25.6 & 50.1 & 0.005 \\
\hline Expectation of further suffering of patient & 53.8 & 52.9 & 1.00 \\
\hline No prospect of improvement & 84.4 & 81.9 & 0.66 \\
\hline Life not to be prolonged needlessly & 39.9 & 62.9 & 0.007 \\
\hline Expectation of low quality of life & 56.3 & 54.3 & 0.86 \\
\hline Unbearable situation for the family & 17.0 & 38.2 & 0.007 \\
\hline Loss of dignity & 51.1 & 43.5 & 0.40 \\
\hline Other & 0.0 & 6.2 & 0.05 \\
\hline
\end{tabular}

*Percentages are weighted to correct for the disproportionate stratification of deaths and for differences in the distribution of patient characteristics (sex, age, province in which death occurred, place of death and cause of death) between study sample and all deaths.

Percentages may not total 100 because of rounding.

tEuthanasia and assisted suicide.

‡One case is missing for "decision discussed with patient" and for "reason for decision"; 11 cases are missing for "reason for not discussing decision with patient."

$\S$ Calculated where applicable using Fisher exact test, for comparison between physician-assisted death with and without explicit request from the patient.

**Multiple answers were possible. Reasons given were selected from prestructured answers.

††Advance directive for end-of-life care, not for euthanasia. 
treatment of the terminal illness, were more likely to have cure as a goal of treatment in the last week, had a shorter estimated time by which life was shortened and more often involved the administration of opioids alone.

Our finding that euthanasia and assisted suicide were typically performed in younger patients, patients with cancer and patients dying at home is consistent with findings from other studies. ${ }^{11,18-21}$ Our finding that the use of life-ending drugs without explicit patient request occurred predominantly in hospital and among patients 80 years or older who were mostly in a coma or had dementia fits the description of "vulnerable" patient groups at risk of life-ending without request. $^{7-10}$ Attention should therefore be paid to protecting these patient groups from such practices. However, when compared with all deaths in Flanders, elderly patients and patients dying of diseases of the nervous system (including dementia) were not proportionally at greater risk of this practice than other patient groups. In the Netherlands in 2005, use of life-ending drugs without explicit request was most often performed by clinical specialists (i.e., in hospital), but occurred relatively infrequently in older patients. ${ }^{11}$

The differences we observed in demographic and clinical

Table 3: Length of treatment, primary goal of treatment and estimated time by which life was shortened in physician-assisted deaths

\begin{tabular}{|c|c|c|c|}
\hline \multirow[b]{2}{*}{ Process } & \multicolumn{2}{|c|}{$\begin{array}{c}\text { Physician-assisted deaths; } \\
\text { weighted \%* }\end{array}$} & \multirow[b]{2}{*}{$p$ value§ } \\
\hline & $\begin{array}{c}\text { With patient's } \\
\text { explicit request } \dagger \\
n=142\end{array}$ & $\begin{array}{c}\text { Without patient's } \\
\text { explicit request } \\
n=66 \ddagger\end{array}$ & \\
\hline $\begin{array}{l}\text { Length of treatment } \\
\text { of terminal illness }\end{array}$ & & & $<0.001$ \\
\hline$<1$ month & 9.6 & 46.1 & \\
\hline $1-6$ months & 10.2 & 13.8 & \\
\hline$>6$ months & 80.3 & 40.0 & \\
\hline $\begin{array}{l}\text { Primary goal of } \\
\text { treatment during } \\
\text { week before death }\end{array}$ & & & 0.013 \\
\hline Cure & 1.2 & 14.6 & \\
\hline $\begin{array}{l}\text { Prolongation of } \\
\text { life }\end{array}$ & 4.6 & 4.9 & \\
\hline Comfort & 94.3 & 80.5 & \\
\hline $\begin{array}{l}\text { Estimated time by } \\
\text { which life was } \\
\text { shortened }\end{array}$ & & & $<0.001$ \\
\hline$<1$ day & 11.4 & 47.9 & \\
\hline 1-7 days & 44.1 & 38.4 & \\
\hline$\geq 1$ week & 44.5 & 13.6 & \\
\hline
\end{tabular}

*Percentages are weighted to correct for the disproportionate stratification of deaths and for differences in the distribution of patient characteristics (sex, age, province in which death occurred, place of death and cause of death) between study sample and all deaths. Percentages may not total 100 because of rounding. tEuthanasia and assisted suicide. Missing cases: 1 for length of treatment, 2 for primary goal of treatment and 1 for estimated time by which life was shortened. ¥Missing cases: 1 for length of treatment, 3 for primary goal of treatment and 1 for estimated time by which life was shortened.

$\S$ Calculated using Fisher exact test, for comparison between physicianassisted death with and without explicit request from the patient.

characteristics between the cases of euthanasia or assisted suicide and those of life-ending drug use without an explicit patient request likely reflect differences in the illness trajectories of the patients concerned. Four out of five cases of euthanasia or assisted suicide involved patients with terminal

Table 4: Information reported about the use of life-ending drugs in physician-assisted deaths*

Physician-assisted death, weighted \%*

With patient's Without patient's explicit request $\dagger$ explicit request

Information $\quad n=142 \quad n=66 \ddagger \quad p$ value

Number of drugs

used

1

$\geq 2$

33.2

66.8

Type of drugs used

Muscle relaxant

Muscle relaxant and barbiturate

Muscle relaxant and drug other than barbiturate

Barbiturate

Barbiturate and drug other than muscle relaxant

Opioid

Opioid and drug other than muscle relaxant and

barbiturate

Benzodiazepine

Person who

administered drugs

Physician

Physician and

nurse

Nurse

Patient

Physician and

patient

someone else**

Physician present

during

administration $\uparrow$

6.4

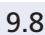

9.5

21.9

21.9

1.0
Nurse and

$\begin{array}{rl}0.5 & - \\ 29.0 & 0.9\end{array}$

48.7

46.6

2.7

51.4

48.6

$<0.001$

9

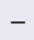

0

*Percentages are weighted to correct for the disproportionate stratification of deaths and for differences in the distribution of patient characteristics between study sample and all deaths. Percentages may not total 100 because of rounding. tEuthanasia and assisted suicide. Two cases missing for number of drugs used and for drugs used.

¥One case missing for number of drugs used and for drugs used.

$\S$ Calculated using Fisher exact test, for comparison between physician-assisted death with and without explicit request from the patient.

$* *$ Relative of the patient.

t+Includes cases in which physician administered drugs or was present during administration of drugs by someone else. 
cancer, which generally has a predictable illness trajectory. For these patients, much time can pass between diagnosis and death, which creates the opportunity for anticipatory decisionmaking. In contrast, in the group without an explicit patient request, most of the patients had diseases other than cancer, which have less predictable end-of-life trajectories. ${ }^{22,23}$ In addition, with cure being the main goal of treatment in the last week for some of these patients, and with the length of treatment of the terminal illness often being less than one month, we believe that the use of life-ending drugs without explicit patient request often involved chronically ill patients whose general condition suddenly and drastically deteriorated to a point that left them permanently unable to communicate. In these situations, as is apparent from our findings, physicians need to decide on a course of action together with the patient's family, which may result in a conflict of interest. This underscores the importance of advance care planning with family and caregivers, and of communication regarding the patient's wishes should he or she become comatose or incompetent. Such measures will undoubtedly limit the number of cases of life-ending without explicit patient request.

Physicians in our study who indicated an intention to hasten the patient's death without an explicit request from the patient most often used opioids, alone or with benzodiazepines. The use of opioids for ending life are discouraged because the patient may regain consciousness and because the procedure can take longer than expected. ${ }^{24-26}$ Furthermore, the life-shortening effect of opioids is subject to speculation. Recent studies have shown that the actual effect on the end of life is prone to overestimation. ${ }^{27-29}$ The estimated time by which life was shortened in many of the cases in our study was already very limited, especially compared with the estimated time in the cases of euthanasia and assisted suicide. We also found that, although physicians specified an intention to hasten death, opioids were often given in doses that were not higher than needed to relieve the patient's pain. This suggests that the practice of using life-ending drugs without an explicit patient request in reality resembles more intensified pain alleviation with a "double effect," and death was in many cases not hastened. The problem may also exist in other countries; for example, in the study in the Netherlands, opioids were also frequently administered to end life without an explicit patient request. ${ }^{11,20,27}$ This points to the need for education of caregivers about misconceptions of opioid use.

We found that the use of life-ending drugs without a patient's explicit request occurred more often in Flanders, Belgium, than in other countries, including the Netherlands, where euthanasia is also legal. ${ }^{11,13,16}$ Flemish physicians have been shown to be more open to this practice than physicians elsewhere, ${ }^{30}$ which suggests a larger degree of paternalistic attitudes. This being said, its occurrence has not risen since the legalization of euthanasia in Belgium. On the contrary, the rate dropped from $3.2 \%$ in 1998 to $1.8 \%$ in $2007 .{ }^{12}$ In the Netherlands, the rate dropped slightly after legalization, from $0.7 \%$ to $0.4 \% .^{11}$ Although legalization of euthanasia seems to have had an impact, more efforts are needed to further reduce the occurrence of life-ending drug use without an explicit request from the patient.

\section{Limitations}

Our study is limited because we could not exclude some degree of nonresponse bias. However, by obtaining an acceptable response rate from a large population sample and weighting for differences with all deaths, we believe the results to be representative of all deaths. Another limitation is that the study provides information only from the physicians' perspective. Also, our study does not permit in-depth case analysis, which impedes interpretation of the contents of discussion and of reported motivations in the decision-making process.

\section{Conclusion}

Our study showed that physician-assisted death with an explicit request from the patient (euthanasia and assisted suicide) and use of life-ending drugs without an explicit request were distinct types of end-of-life decisions that occurred in different patient groups and under different circumstances. Unlike euthanasia and assisted suicide, the use of life-ending drugs without an explicit patient request often involved patients with diseases other than cancer, which have an unpredictable end-of-life trajectory. This finding underscores the need for advance care planning. Finally, misconceptions seem to persist about the life-shortening effects of opioid use. Future research should closely monitor both types of physician-assisted deaths in various countries with and without legal regulations for euthanasia.

This article has been peer reviewed.

Competing interests: None declared.

Contributors: All of the authors were involved in the design of the study, the collection, analysis and interpretation of data, and the writing or revising of the manuscript. The corresponding author had full access to all of the data in the study and had final responsibility for the decision to submit for publication. All of the authors approved the final version of the manuscript submitted for publication.

Acknowledgements: The authors primarily thank the Flemish Agency for Care and Health and lawyer Wim De Brock for their participation in the organization of the data collection. Geert Pousset deserves special praise for his part in conducting the data collection. They further thank the Belgian Medical Disciplinary Board for recommending the study. They are deeply indebted to all physicians who participated in this study.

Funding: This study was funded by the Institute for the Promotion of Innovation by Science and Technology — Flanders (IWT Vlaanderen - project IWT-SBO 050158).

\section{REFERENCES}

1. Law concerning euthanasia. Belgian official collection of the laws - 2002 June 22 [Dutch]. Available: www.health.fgov.be/euthanasie (accessed 2010 Apr. 29).

2. Termination of Life on Request and Assisted Suicide (Review Procedures) Act [Dutch]. The Hague (the Netherlands): Government of the Netherlands; 2002. Available: www.toetsingscommissieseuthanasie.nl/wetgeving (accessed $2010 \mathrm{Apr}$. 29).

3. Proposition de loi sur l'euthanasie et l'assistance au suicide [dossier parlementaires $\mathrm{n}^{\circ}$ 4909]. Government of Luxembourg; 2008. Available: www.gouvernement.lu/salle _presse/actualite/2008/12-decembre/18-chd/18-4909.pdf (accessed 2009 Feb. 3).

4. Oregon Death with Dignity Act. Oregon Revised Statute 127.800-127.995. Available: http://egov.oregon.gov/DHS/ph/pas/docs/statute.pdf (accessed 2010 Apr. 29).

5. Washington Death with Dignity Act, Initiative measure 1000. RCW 70.245. Available: http://wei.secstate.wa.gov/osos/en/Documents/I1000-Text\%20for\%20web.pdf (accessed 2010 Apr. 29).

6. Collier R. Euthanasia debate reignited. CMAJ 2009;181:463-4.

7. Lewis P. The empirical slippery slope. From voluntary to non-voluntary euthanasia. J Law Med Ethics 2007;35:197-210.

8. George RJD, Finlay IG, Jeffrey D. Legalised euthanasia will violate the rights of vulnerable patients. BMJ 2005;331:684-5. 
9. Battin MP, van der Heide A, Ganzini L, et al. Legal physician-assisted dying in Oregon and the Netherlands: evidence concerning the impact on patients in "vulnerable" groups. J Med Ethics 2007;33:591-7.

10. Quill TE. Physician assisted death in vulnerable patient groups. BMJ 2007;335:625-6.

11. van der Heide A, Onwuteaka-Philipsen B, Rurup ML, et al. End-of-life practices in the Netherlands under the euthanasia act. N Engl J Med 2007;356:1957-65.

12. Bilsen J, Cohen J, Chambaere K, et al. Medical end-of-life practices under the euthanasia law in Belgium. N Engl J Med 2009;361:1119-21.

13. van der Heide A, Deliens L, Faisst K, et al. End-of-life decision-making in six European countries: descriptive study. Lancet 2003;362:345-50.

14. Kuhse H, Singer P, Baume P, et al. End-of-life decisions in Australian medical practice. Med J Aust 1997;166:191-6.

15. Meier DE, Emmons CA, Wallenstein S, et al. A national survey of physician-assisted suicide and euthanasia in the United States. N Engl J Med 1998;338:1193-201.

16. Seale C. National survey of end-of-life decisions made by UK medical practitioners. Palliat Med 2006;20:3-10.

17. Chambaere K, Bilsen J, Cohen J, et al. A post-mortem survey on end-of-life decisions using a representative sample of death certificates in Flanders, Belgium research protocol. BMC Public Health 2008;8:299.

18. Deliens L, Mortier F, Bilsen J, et al. End-of-life decisions in medical practice in Flanders, Belgium: a nationwide survey. Lancet 2000;356:1806-11.

19. Onwuteaka-Philipsen BD, van der Heide A, Koper D, et al. Euthanasia and othe end-of-life decisions in the Netherlands in 1990, 1995, and 2001. Lancet 2003;362:395-9.

20. Rietjens JA, Bilsen J, Fischer S, et al. Using drugs to end life without an explicit request of the patient. Death Stud 2007;31:205-21.

21. Seale C. End-of-life decisions in the UK involving medical practitioners. Palliat Med 2009;23:198-204.
22. Murray SA, Kendall M, Boyd K, et al. Illness trajectories and palliative care. BMJ 2005;330:1007-11.

23. Murtagh FE, Preston M, Higginson I. Patterns of dying: palliative care for nonmalignant disease. Clin Med 2004;4:39-44.

24. Royal Dutch Society for the Advancement of Pharmacy. Utilization and preparations of euthanasia drugs. The Hague (the Netherlands): The Society; 1998.

25. Swarte NB, Heintz AP. Guidelines for an acceptable euthanasia procedure. Best Pract Res Clin Obstet Gynaecol 2001;15:313-21.

26. Groenewoud JH, van der Heide A, Onwuteaka-Philipsen B, et al. Clinical problems with the performance of euthanasia and physician-assisted suicide in the Netherlands. N Engl J Med 2000;342:551-6.

27. Rurup ML, Borgsteede SD, van der Heide A, et al. Trends in the use of opioids at the end of life and the expected effects on hastening death. J Pain Symptom Manage 2009;37:144-55.

28. Sykes N, Thorns A. The use of opioids and sedatives at the end of life. Lancet Oncol 2003;4:312-8.

29. Morita T, Tsunoda J, Inoue S, et al. Effects of high dose opioids and sedatives on survival in terminally ill cancer patients. J Pain Symptom Manage 2001;21:282-9.

30. Cohen J, van Delden JJ, Mortier F, et al. The influence of physicians' life stance on attitudes towards end-of-life decisions and actual end-of-life decision-making in six countries. J Med Ethics 2008;34:247-53.

Correspondence to: Kenneth Chambaere, End-of-Life Care

Research Group, Vrije Universiteit Brussel, Laarbeeklaan 103, 1090 Brussels (Jette),Belgium; kchambae@vub.ac.be

\section{In type 2 diabetes, you may need more than basal insulin when...}

your patient has FPG

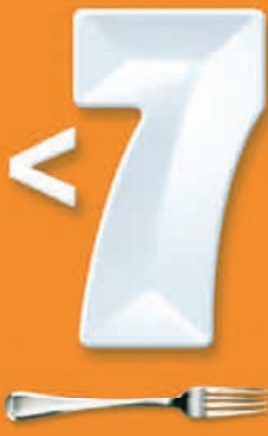

$\mathrm{mmol} / \mathrm{L}$ but $\mathbf{A} 1 \mathbf{C}$ is still

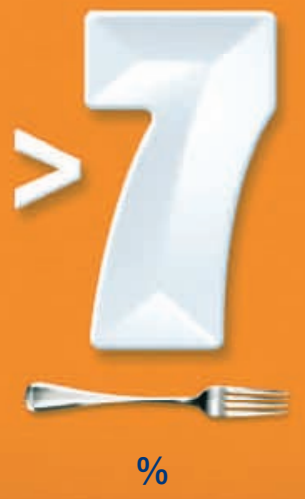

What's Your PROTOCOL?

FPG = Fasting Plasma Glucose

Target glycemic ranges recommended by the Canadian Diabetes Association 2008 Clinical Practice Guidelines for the Prevention and Management of Diabetes in Canada.

WhatsYourProtocol.ca

NR992E/06/10 